\title{
Localização dos Setores Produtivos na Geoeconomia da Microrregião do Rio Formoso, $\mathrm{TO}^{1}$
}

\author{
Nilton Marques Oliveira² \\ Ana Lucia de Medeiros ${ }^{3}$ \\ Gaspar Carmanhan da Silveira Neto ${ }^{4}$ \\ Elvis Ribeiro Lopes $^{5}$
}

\begin{abstract}
Resumo
O objetivo deste artigo foi estimar e analisar os indicadores de análise regional dos ramos de atividades produtivas na microrregião do Rio Formoso, Tocantins, entre 2005 e 2015 . O referencial teórico adotado foi o conceito de economia regional numa perspectiva sobre a teoria de localização dos setores produtivos. Foram estimados o quociente locacional, o coeficiente de associação geográfica e o multiplicador de emprego. Os dados de emprego formal foram coletados junto à Relação Anual de Informações Sociais (RAIS) do Ministério do Trabalho e Emprego (MTE). Os principais resultados sugerem que, na distribuição percentual entre os treze municípios analisados, o ramo de atividades que mais emprega é a administração pública. Os principais ramos industriais são de origem agropecuária e extração mineral. O multiplicador de emprego para Rio Formoso era de 3,68 em 2005, caindo para 2,50 em 2015. Esse dado significa que a geração de um emprego de base implica duas vezes e meia na geração de atividade doméstica local para os municípios de toda a microrregião. Quanto à análise da associação geográfica dos ramos de atividades do Rio Formoso, no ano de 2015, o setor de indústria de transformação teve associação dinâmica com a construção civil, comércio e serviços. Esses setores, de certa forma, drenam e atraem as atividades produtivas da microrregião.
\end{abstract}

Palavras-chave: Economia Regional. Forças Aglomerativas. Rio Formoso - TO.

\begin{abstract}
This paper aimed to estimate and analyze the indicators of regional analysis of productive activities branches in Rio Formoso, microregion of Tocantins State (TO), Brazil, from 2005 to 2015. The concept of regional economy under a perspective on the localization theory of the productive sectors was adopted as theoretical reference. The locational quotient, the geographic association coefficient, and the employment multiplier were estimated. Formal employment data were collected in the Annual Report on Social Information (ARSI) from the Ministry of Labor and Employment (MLE). The main results suggest that, in the percentage distribution among the thirteen analyzed municipalities, the activities branch that hires more people is the public administration. The main industrial branches are originated from agricultural activities and mineral extraction. The employment multiplier for Rio Formoso was 3.68 in 2005 and fell down to 2.50 in 2015. This data means two and a half times the generation of local domestic activity for the municipalities of the entire microregion, when generating a basic employment. Regarding the analysis of the geographical association of the activities branches of Rio Formoso in 2015, the sector of transformation industry had dynamic association with the civil construction, trade, and services. Somehow, these sectors drain and attract the productive activities of the microregion.
\end{abstract}

Keywords: Regional Economy. Agglomerative forces. Rio Formoso. Tocantins State (TO).

\footnotetext{
${ }^{1}$ Esta pesquisa teve apoio financeiro da Universidade Federal do Tocantins (Propesq/ UFT)

2 Doutor em Desenvolvimento Regional e Agronegócio. Professor do Programa de Pós-graduação em Desenvolvimento Regional da Universidade Federal do Tocantins - UFT.niltonmarques@uft.edu.br

${ }^{3}$ Doutora em Administração. Professora do Mestrado Profissional em Gestão de Políticas Públicas (GESPOL) e do Mestrado Profissional em Administração Pública (PROFIAP) da Universidade Federal do Tocantins - UFT. analucia@mail.uft.edu.br

${ }^{4}$ Economista. Universidade Federal do Tocantins - UFT. gasparcarmanhan16@gmail.com

${ }^{5}$ Economista. Universidade Federal do Tocantins - UFT. elvisribeiro@mail.uft.edu.br
} 


\section{Introdução}

Este artigo tem por objetivo estimar e analisar os indicadores de análise regional dos ramos de atividades produtivas na geoeconomia da microrregião do Rio Formoso entre 2005 e 2015. A análise recai nos ramos produtivos mais significativos, seu perfil aglomerativo/associativo e sua capacidade de alocar mão de obra nos setores mais competitivos da microrregião, fornecendo subsídios às políticas públicas de emprego e renda.

A microrregião do Rio Formoso está localizada na porção Sudeste da Mesorregião Ocidental do Tocantins e é a maior em extensão territorial $\left(51.405,34 \mathrm{~km}^{2}\right)$, sendo aproximadamente $22,7 \%$ do estado do Tocantins, com uma população de 118.052 hab., e sua densidade populacional é de $2,2 \mathrm{hab} / \mathrm{km}^{2}$ (IBGE, 2015). A região faz divisa com outras microrregiões tocantinenses: ao leste, microrregiões de Porto Nacional e Gurupi, e, ao norte, microrregião de Miracema do Tocantins. A parte oeste do território faz fronteira com os estados do Mato Grosso - com maior parcela - e do Pará. Ao sul, a microrregião faz divisa com Goiás. Rio Formoso se subdivide em treze municípios: Araguaçu, Chapada de Areia, Cristalândia, Dueré, Fátima, Formoso do Araguaia, Lagoa da Confusão, Nova Rosalândia, Oliveira de Fátima, Paraíso do Tocantins, Pium, Pugmil e Sandolândia (Figura 1).

Figura 1 - Localização dos municípios da microrregião de Rio Formoso - Tocantins

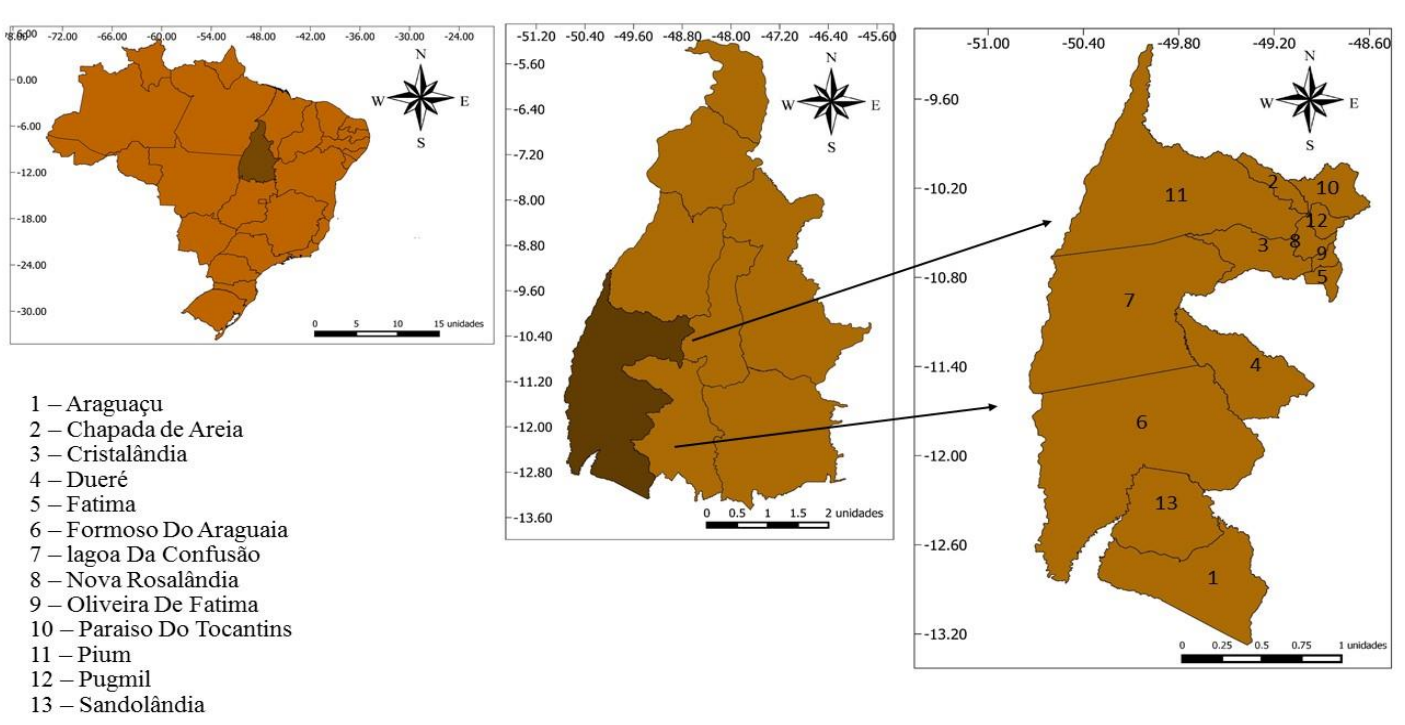

Fonte: IBGE (2015), adaptado pelos autores. 
A economia dessa microrregião se baseia no serviço, no comércio, na administração pública, na agricultura (arroz, milho, feijão, soja, melancia), na pecuária e na criação de animais de pequeno porte. A especificidade dessa microrregião está em ter em seu território a maior ilha fluvial do mundo (Ilha do Bananal) e abarcar os povos indígenas Karajá, Javaés e Avá-Canoeiros (FRANÇA; COSTA, 2016).

Na década de 1970, foi implementado na região do vale do Araguaia o projeto Rio Formoso, que tinha como objetivo expandir a fronteira agrícola, com a implantação de culturas irrigadas de grãos, especialmente o arroz e a soja, localizado às margens do Rio Formoso, afluente oriental do rio Javaés. A área total do projeto é de aproximadamente 65 mil hectares, divididos em subáreas destinadas à irrigação. Tem-se acesso ao projeto pela BR-242, que se inicia na Belém-Brasília (BR-153), próximo à cidade de Figueirópolis. É por meio dessas rodovias que se escoa a produção para as regiões Norte e Sul do Brasil (BARBOSA, 1996).

Nesse sentido, a Teoria da Base de Exportação visa complementar a discussão do processo de desenvolvimento dessa microrregião. Essa foi a primeira teoria de crescimento regional a inserir a exportação como fator-chave para o crescimento de uma localidade. 0 aumento da produção das atividades voltadas à base exerceria um efeito multiplicador sobre as atividades não básicas (NORTH, 1955; 1977).

Alguns países, principalmente os do Sudeste asiático, possuem muitas dessas características em seu processo de desenvolvimento. Coreia do Sul, China, entre outros, tiveram crescimento e desenvolvimento a partir das exportações, além da produção com avançada tecnologia a partir da década de 1980 (OLIVEIRA; NOBREGA; MEDEIROS, 2012).

Nas palavras de Diniz e Crocco (2006), o desenvolvimento regional compreende uma análise de fatores sociais e econômicos no interior de uma região, fatores esses que compõem a mobilidade espacial do capital, do trabalho e das inovações. Tais fatores, quando bem empregado em uma determinada região, podem reduzir ou acelerar as desigualdades regionais.

Há três aspectos teóricos que conseguem explicar o movimento da atividade produtiva no espaço. O primeiro é a intervenção do Estado na economia, o segundo se refere ao papel dos recursos naturais, historicamente a principal causa para abertura de fronteiras econômicas e o terceiro seriam os fatores especificamente espaciais. Este último, 
em particular, se refere à dispersão dos recursos que influenciam a diversificação das atividades urbano-industriais (FERRERA DE LIMA; ALVES, 2008).

Isso posto, este artigo está divido em quatro partes. Além desta introdução, a segunda parte apresenta uma breve discussão sobre a Teoria de Base Econômica; a terceira parte expõe os procedimentos metodológicos; a quarta apresenta e discute os principais resultados; por fim, não menos importante, as considerações finais sumarizam o artigo. A próxima seção tem por objetivo contextualizar a Teoria de Base Econômica ou Base de Exportação.

\section{Teoria de base econômica}

Os primeiros conceitos sobre a Teoria da Base de Exportação foram formulados por geógrafos interessados nos estudos do processo de desenvolvimento e ocupação das cidades de uma região. Os estudos sobre o assunto dividiram a região em duas atividades: básicas e não básicas. A primeira está relacionada ao desenvolvimento das atividades voltadas ao mercado externo, isto é, processos produtivos destinados à exportação, enquanto a não básica está relacionada à produção de bens e serviços voltados ao mercado interno (OLIVEIRA; NOBREGA; MEDEIROS, 2012).

A obra seminal de North (1955), Location theory and regional economic growth, trata sobre um dos primeiros estudos que se refere aos efeitos da base de exportação no desenvolvimento de uma região. Ele destaca que não aceitava, nas argumentações convencionais, a explicação do processo de desenvolvimento regional de algumas regiões dos Estados Unidos.

Nesse sentido, North (1977) argumenta que o desenvolvimento regional passa, em um primeiro momento, pela base econômica (base de exportação). Essa teoria, que serviu de suporte para a compreensão do crescimento das regiões, trata sobre a localização das atividades produtivas.

Souza (1980) discute que a Teoria da Base de Exportação foi a primeira teoria de crescimento regional a inserir a exportação como fator-chave para o crescimento de uma localidade. Ele enfatiza que as exportações exercem um efeito multiplicador sobre a economia. Assim, países que se voltaram para o mercado externo obtiveram um processo de 
desenvolvimento mais rápido, como foi o caso dos Estados Unidos e do Canadá.

A Teoria da Base Econômica possibilita a forma mais simples de modelo de renda regional, sendo que sua importância está no fato de que serve como estrutura teórica para estudos empíricos de regiões (RICHARDSON, 1975). A Teoria da Base Econômica explica essas relações inter-regionais que envolvem o fluxo de mercadorias, de pessoas e de serviços, bem como avalia as implicações desses fluxos entre a região e o restante da economia mundial.

Segundo Richardson (1975), as teorias convencionais obedeciam às seguintes etapas: i) a necessidade de haver economia de subsistência, a qual deveria ser autossuficiente e agrícola; ii) a ênfase no desenvolvimento do comércio e na melhoria do transporte; iii) o surgimento de comercialização inter-regional; iv) o processo de industrialização; e v) o estágio final, caracterizado pela especialização em atividades terciárias para exportação.

Partindo da Teoria da Base Econômica, Schwartzman (1975) explica que o desenvolvimento de uma região depende do dinamismo dessa base e de sua difusão para o resto da economia regional, ou seja, deve apresentar duas condições necessárias para o desenvolvimento: i) manutenção do dinamismo do produto de exportação; ii) difusão do dinamismo para outros setores da economia.

A Teoria da Base Econômica possibilita a forma mais simples de modelo de renda regional, e sua importância está no fato de que serve como estrutura teórica para estudos empíricos de regiões. Quando se tem como objetivo estudar o desenvolvimento econômico de uma região, um dos problemas fundamentais é compreender suas relações com as demais regiões do sistema nacional, com o exterior. A Teoria da Base de Exportação explica essas relações inter-regionais que envolvem o fluxo de mercadorias, de pessoas e de serviços, bem como avalia as implicações desses fluxos entre a região e o restante da economia mundial (RICHARDSON, 1975). A próxima seção tem por objetivo descrever a metodologia dos indicadores de análise regional para a microrregião de Rio Formoso entre 2005 e 2015. 


\section{Procedimentos metodológicos}

A análise regional tem por escopo quantificar setores ou ramos de atividades econômicas mais dinâmicas em determinada região, a partir das medidas de localização. Nesta pesquisa, foram explorados três indicadores: Quociente Locacional (QL), Coeficiente de Associação Geográfica e Multiplicador de Emprego. Segundo Haddad (1989), essas medidas fornecem elementos explicativos para o conhecimento dos padrões de localização das atividades produtivas e sua capacidade de atração e adensamento ao longo do tempo.

A variável utilizada na análise foi o emprego formal, distribuído nos oito setores de atividade. Pressupõe-se que os setores mais dinâmicos empreguem mais mão de obra no decorrer do tempo. Por outro lado, a ocupação da mão de obra reflete-se na geração e na distribuição da renda regional ou local, o que estimula o consumo e, consequentemente, a dinâmica da região. Os dados de emprego formal foram coletados da Relação Anual de Informações Sociais (RAIS) do Ministério do Trabalho e Emprego (TEM, 2016). O período de análise foram os anos de 2005 e 2015.

Com a definição da variável utilizada, as atividades foram agrupadas de acordo com a classificação dos ramos de atividades produtivas e dos subsetores de atividade econômica do Instituo Brasileiro de Geografia e Estatística (IBGE): extrativa mineral, indústria de transformação, serviços industriais de utilidade pública, construção civil, comércio, serviços, administração pública e agropecuária, extração vegetal, caça e pesca. A partir dessa distribuição, tem-se as seguintes equações: mão de obra no ramo produtivo $i$ do município $j$ :

$\mathrm{E}_{i j}=$ mão de obra no ramo produtivo $i$ do município $j$;

$\sum_{j} E i j=$ somatório da mão de obra no ramo produtivo $i$ do município $j$; (2)

$\sum_{i} E_{i j}=$ somatório da mão de obra em todos os ramos produtivos do município $j$; (3)

$\sum_{i} \sum_{j} E i j=$ somatório da mão de obra em todos os ramos produtivos e todos os municípios. (4)

A partir das equações 1, 2, 3, 4, organizou-se o Quadro 1, que apresenta as medidas de localização e o multiplicador de emprego. As medidas quociente locacional e coeficiente de associação geográfica são de natureza setorial e se preocupam com a localização das atividades produtivas entre os municípios, ou seja, procuram identificar padrões de 
concentração ou dispersão de mão de obra por ramos de atividade, em um determinado período.

\section{Quadro 1 - Medidas de localização e multiplicador do emprego}

\begin{tabular}{|c|c|c|}
\hline Indicador & Equação & Interpretação dos resultados \\
\hline Quociente Locacional (QL) & $\mathrm{QL}_{\mathrm{ij}}=\frac{\mathrm{E}_{\mathrm{ij}} / \sum_{\mathrm{j}} \mathrm{E}_{\mathrm{ij}}}{\sum_{\mathrm{i}} \mathrm{E}_{\mathrm{ij}} / \sum_{\mathrm{i}} \sum_{\mathrm{j}} \mathrm{E}_{\mathrm{ij}}}$ & $\begin{array}{l}\text { QL } \geq 1 \text { localização significativa } \\
0,50 \leq Q L \leq 0,99 / \text { localização média } \\
Q L \leq 0,49 \text { localização fraca }\end{array}$ \\
\hline $\begin{array}{l}\text { Coeficiente de Associação } \\
\text { Geográfica (Cag) }\end{array}$ & $\mathrm{Cag}_{\mathrm{ik}}=\frac{\sum_{\mathrm{j}}\left(\mid\left(\mathrm{E}_{\mathrm{ij}} / \sum_{\mathrm{i}}^{\text {setor } \mathrm{E}} \mathrm{E}_{\mathrm{ij}}\right)-\left(\mathrm{E}_{\mathrm{ij}} / \sum_{\mathrm{k}}^{\text {setor } \mathrm{E}}\right)\right.}{2}$ & $\begin{array}{l}\text { Associação Significativa: } \\
0,01 \leq \text { Cag } \leq 0,32 \\
\text { Associação Média: } \\
0,33 \leq \text { Cag } \leq 0,67 \\
\text { Associação Fraca: } \\
0,68 \leq \text { Cag } \leq 1,00\end{array}$ \\
\hline $\begin{array}{l}\text { Emprego Básico e Não } \\
\text { Básico }\end{array}$ & $B_{i j}=S_{i j}-S_{t j}\left(\frac{N_{i}}{N_{t}}\right)$ & Emprego Básico: QL $\geq 1$ \\
\hline $\begin{array}{l}\text { Multiplicador do Emprego } \\
\text { Básico }\end{array}$ & $\begin{array}{l}\mathrm{EN}=\alpha \mathrm{E} \text { para }(0>\mathrm{a}>1) \\
\mathrm{E}=\alpha \mathrm{E}+\mathrm{EB} \\
\mathrm{EB}=\mathrm{E}-\alpha \mathrm{E} \\
\mathrm{EB}=\mathrm{E}(1-\alpha) \\
\mathrm{E}=1 / 1-\alpha \mathrm{EB} \text { ou } \\
\mathrm{E}=\mathrm{K}^{*} \mathrm{~EB}\end{array}$ & $\begin{array}{l}\text { Cada emprego gerado na atividade } \\
\text { básica gera }(X+1) \text { unidade de } \\
\text { emprego na atividade não básica do } \\
\text { município. }\end{array}$ \\
\hline
\end{tabular}

Fonte: Haddad (1989); Oliveira (2015).

A equação do Quociente Locacional (QL), apresentada no Quadro 1, é utilizada para comparar a participação percentual da mão de obra do município com a participação percentual no total do Estado. A importância do município no contexto estadual, em relação ao setor estudado, é demonstrada quando QL assume valor $\geq 1$, fazendo menção às atividades básicas. Os setores com valores $<1$ seriam os não básicos, ou seja, a atividade produtiva não está relativamente concentrada na unidade territorial. Nesse caso, em unidades territoriais em que um determinado setor apresenta um $Q L<1$, sua importância é relativamente inferior à região de referência desse setor (PIFFER, 2012; ALVES, 2012).

O coeficiente de associação geográfica mostra a associação geográfica entre dois setores ( $i$ e $k$ ), comparando as distribuições percentuais da mão de obra entre os municípios. 
Seus valores variam de 0 - que significam que o setor $i$ estará distribuído regionalmente da mesma forma que o setor $k$, mostrando que os padrões locacionais dos dois setores estão associados geograficamente - até 1 . Isso geralmente ocorre para aqueles setores que são complementares no processo produtivo, em que a existência de um exige a existência do outro setor para que o processo produtivo ocorra com maior eficiência (ALVES, 2012).

Em complemento à análise do QL, faz-se necessário o cálculo do multiplicador do emprego básico, que indica os componentes necessários para a formação da base econômica. Da mesma forma que a atividade básica, o emprego básico é aquele que apresenta $Q L>1$, também chamado de emprego ou atividade motora.

O cálculo para verificar os empregos básicos e não básicos de uma região é realizado por meio da fórmula descrita por Piffer (2009) - (Quadro 1) - em que $B_{i j}$ é o emprego básico da atividade $i$ na região $j$; $S_{i j}$ é o emprego da atividade $i$ na região $j ; S_{t j}$ é o emprego total na região $j$; $N_{i}$ é o total de emprego da atividade $i$ no Estado; e $N_{t}$ é o total de empregos no Estado. Se o emprego estiver ligado às atividades básicas de exportação, $B_{i j}$ será maior que a unidade.

O multiplicador do emprego básico é utilizado com o intuito de quantificar o impacto do emprego básico no município - (Quadro 1) -, em que EN é o emprego não básico; $E B$ é o emprego básico; $\alpha$ é o coeficiente de emprego; $E$ é o emprego total; e $K$ é o multiplicador do emprego da região. O multiplicador do emprego mostra o quanto é gerado de emprego nos ramos de atividades não básicas, dado um acréscimo de um emprego nos ramos de atividades básicas (PIFFER, 2009). Na próxima seção são apresentados e discutidos os principais resultados da análise regional dos treze municípios e seu dinamismo na geoeconomia da microrregião de Rio Formoso, estado do Tocantins.

\section{A localização dos setores produtivos na geoeconomia da microrregião do Rio Formoso, Tocantins}

Analisando a distribuição percentual da mão de obra (emprego) entre os treze municípios da microrregião de Rio Formoso, o ramo de atividade que teve maior concentração foi o da administração pública. Em alguns municípios, essa participação passou dos $80 \%$, em 2005, como foi o caso dos municípios Chapada de Areia (2), com 93\%; Nova 
Rosalândia (8), com 82\%; Oliveira de Fátima (9), com 94\%. Em 2015, permaneceu, nesses municípios, a concentração desse setor na atividade econômica.

Os municípios que apresentaram melhor uniformização de mão de obra nos setores produtivos foram Paraíso do Tocantins (10), Lagoa da Confusão (7), Formoso do Araguaia (6). Os setores de atividades de maior dinamismo nesses municípios foram indústria de transformação, agropecuária, comércio, serviço e extrativismo mineral. Observa-se uma irradiação para os municípios ao seu redor, entre eles Cristalândia, Pium, Dueré, Fátima, Pugmil e Sandolândia.

Na sequência, analisa-se o quociente locacional (QL). Os setores de atividades que apresentaram QL maior que 1 em seus respectivos municípios representam a atividadebase, ou seja, a atividade motora da economia local em termos de emprego da força de trabalho. Na Figura 2, observa-se que o setor extrativo mineral apresentou significância nos municípios de Formoso do Araguaia (6), Lagoa da Confusão (7) e Pugmil (12) para o ano de 2005, e nos municípios de Dueré (4), Lagoa da Confusão e Pugmil em 2015. Entre eles, Pugmil foi o município em que o QL do setor se manteve mais expressivo durante os dois anos de análise, valendo uma atenção maior para as causas desse aumento.

O município de Pugmil (12) conta com as atividades de extração de minerais não metálicos: areia, cimento, seixos e cascalho. Em Pugmil - TO, estão instaladas cerca de doze empresas atuantes nessa atividade. A atividade se manteve crescente, com aumento de $20 \%$ na quantidade de emprego para o setor de extrativismo mineral.

A empresa veterana do setor conta com suas atividades iniciadas em 1991, sendo ainda atuante no mercado, demonstrando a relevância dessa atividade para o município. Essa atividade contribui também com o setor da construção civil para a região e para outros estados. 
Figura 2 - QL da indústria extrativa mineral e da indústria de transformação - 2005 e 2015

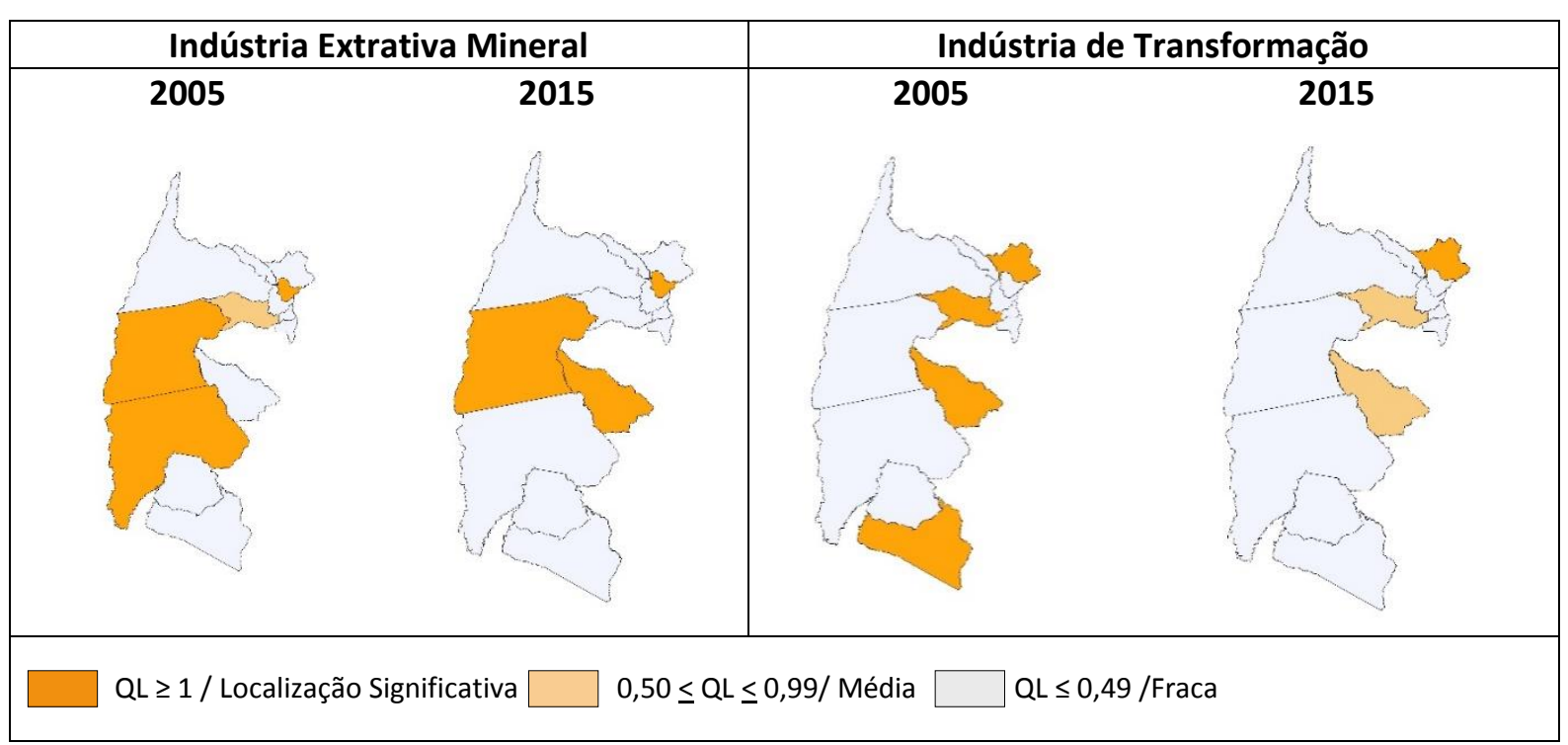

Fonte: Resultados da pesquisa.

No setor de indústria de transformação, o QL de localização significativa em 2005 estava concentrado nos municípios de Araguaçu (1), Cristalândia (3), Dueré (4) e Paraíso do Tocantins (10). Em 2015, Paraíso do Tocantins manteve a forte localização, e os municípios de Cristalândia (3) e Dueré (4) passaram a ter QL mediano (Figura 2).

No município de Paraíso do Tocantins, a $60 \mathrm{~km}$ de Palmas, está instalada a agroindústria Frango Norte, uma das maiores do estado. A empresa contratou, em 2015, mais de 200 empregados. Sua produção de frango abastece o mercado local, o estado do Tocantins e ainda exporta para outras regiões do país e para o mercado externo.

O setor de serviços industriais de utilidade pública se destaca em terceiro lugar na comparação com os setores que apresentam significativa porcentagem de mão de obra empregada, em maior quantidade de municípios (Figura 3). Tanto em 2005 quanto em 2015, o QL do setor de serviços industriais de utilidade pública foi significativo nessa microrregião, o que mostra a importância desse setor entre os municípios que estão em franca expansão de suas atividades básicas em infraestrutura: rede de esgoto, energia elétrica, água encanada e saneamento. 
Figura 3 - QL dos serviços industriais de utilidade pública e construção civil - 2005 e 2015

\begin{tabular}{|c|c|c|}
\hline Serviços Industriais de Utilidade Pública & Construção Civil \\
\hline 2005 & 2015 & 2005 \\
\hline & & \\
\hline
\end{tabular}

Fonte: Resultados da pesquisa.

O setor da construção civil teve fraco desempenho na microrregião tanto em 2005 quanto em 2015. Os municípios que apresentaram o QL maior que 1 nesse setor foram Lagoa da Confusão (7) e Paraíso do Tocantins (10), em 2005; e, em 2015, apenas Paraíso do Tocantins teve localização significativa. O fraco desempenho se deve à crise do setor no Brasil. No Tocantins, não foi diferente, em 2015, mais de 85 mil trabalhadores perderam o emprego. Os setores mais afetados no Tocantins foram a construção civil, que acumulou perda de 2.828 postos de trabalho, e o comércio com 510 postos (MTE, 2015).

A Figura 4 apresenta o QL do comércio e serviços dos treze municípios da microrregião do Rio Formoso. O QL do comércio foi significativo, tanto em 2005 quanto em 2015, em Fátima (5) e Paraíso do Tocantins (10). Paraíso do Tocantins conta com uma população de 48 mil habitantes, sendo ainda importante acesso por meios da BR-153 (Belém-Brasília). Paraíso é referência para os demais municípios da microrregião do Rio Formoso.

O comércio é o grande setor dinâmico do município e transborda para os municípios vizinhos, entre eles Araguaçu (1), Cristalândia (3), Formoso do Araguaia (6) e Lagoa da Confusão (7). Esse setor movimenta mais da metade da economia do município. Com um PIB de R\$ 584 milhões de reais, é a sexta economia do estado do Tocantins (IBGE, 2015). Outra cidade que teve o QL significativo no setor do comércio foi Fátima (5), que tem boa 
infraestrutura local, possui comércio varejista, atende às populações local e do entorno, com mercados, padarias, vestuários e produtos agrícolas (Figura 4).

Figura 4 - QL do comércio e serviços - 2005 e 2015

\begin{tabular}{|c|c|c|}
\hline Comércio & Serviços \\
\hline 2005 & & \\
\hline QL $\geq 1 /$ Localização Significativa $\square 015$
\end{tabular}

Fonte: Resultados da pesquisa.

No setor de serviços, o QL foi significativo nos municípios de Formoso do Araguaia (6), Paraíso do Tocantins (10) e Pugmil (12), em 2005; em 2015, em Cristalândia (3), Fátima (5), Paraíso do Tocantins (10) e Pium (11). Esses municípios dispõem de uma boa rede hoteleira, restaurantes, bares, casas noturnas, lazer para família, boas escolas e faculdades, posto de saúde e hospitais.

A Figura 5 apresenta o QL dos setores da administração pública e da agropecuária, extração vegetal, caça e pesca para a microrregião de Rio Formoso. Nota-se que o setor da administração pública é significativo em quase todos os municípios da microrregião, exceto em Paraíso do Tocantins (10) e Cristalândia (3). Esse QL significativo denota uma forte dependência desse setor na geração de emprego nessas localidades. A dinâmica centra-se no poder local, ou seja, nas prefeituras, enquanto que em Paraíso do Tocantins (10) e Cristalândia (3), a dinâmica centra-se nos setores do comércio e de serviços.

Essa dependência da administração pública foi constatada em Oliveira (2015), segundo o qual grande parte dos municípios do estado do Tocantins possui uma economia de subsistência, grande dependência de transferência de renda, tanto do poder federal 
quanto estadual, não havendo alternativa de gerar emprego no interior do estado, a não ser as prefeituras. Esse é o grande desafio do estado e de toda sociedade (atores sociais, políticos, econômicos e empresariais).

Figura 5 - QL da administração pública e agropecuária, extração vegetal, caça e pesca 2005 e 2015

\begin{tabular}{|c|c|}
\hline Administração Pública & Agropecuária, Extração Vegetal, Caça e Pesca \\
\hline 2005 & \\
\hline
\end{tabular}

Fonte: Resultados da pesquisa.

O QL do setor da agropecuária, extração vegetal, caça e pesca, foi significativo em quase todos os municípios, tanto em 2005 quanto em 2015, exceto em Chapada da Areia (2), Fátima (5), Nova Rosalândia (8), Oliveira de Fátima (9) e Paraíso do Tocantins (10). Nessa microrregião, está localizado o maior plantio de arroz e soja em áreas alagadas, áreas essas que se concentram nos municípios de Dueré (4), Formoso do Araguaia (6), Lagoa da Confusão (7) e Pium (11). O Tocantins é o terceiro maior produtor de arroz irrigado do Brasil. Com uma área de mais de 85 mil ha, a produção foi de 630 mil toneladas de grãos em 2015 (IBGE, 2015).

A seguir, analisa-se o coeficiente de associação geográfica dos setores produtivos da microrregião de Rio Formoso para os anos de 2005 e 2015. Esse coeficiente mostra a possível formação de clusters no município, ou seja, quando o crescimento em um determinado setor tende a transbordar para outros setores na econômica como um todo (Tabela 1, inserida na próxima página). 
O setor de extrativa mineral não apresentou nenhuma associação com os demais setores, não que esse setor seja menos importante. O setor da indústria de transformação, em 2005, foi atrativo para os setores de serviços industriais de utilidade pública, construção civil, comércio e serviços. Em 2015, esse setor teve associação significativa com os setores da construção civil, comércio, serviço e administração pública.

O setor de serviços industriais de utilidade pública, tanto em 2005 quanto em 2015, teve associação forte com os seguintes setores: comércio, serviço e administração pública. 0 setor de construção civil se associou significativamente com o do comércio e serviços, tanto em 2005 quanto em 2015. Já o setor de comércio teve associação forte com o de serviço nos dois períodos analisados.

Tabela 1 - Coeficiente de associação geográfica dos municípios da microrregião do Rio Formoso: 2005 e 2015

\begin{tabular}{|c|c|c|c|c|c|c|c|c|c|c|c|c|c|c|c|c|}
\hline \multirow[t]{2}{*}{$\begin{array}{l}\text { Ramos de } \\
\text { Atividade }\end{array}$} & \multicolumn{2}{|c|}{$\begin{array}{l}\text { Extrativa } \\
\text { Mineral }\end{array}$} & \multicolumn{2}{|c|}{$\begin{array}{l}\text { Indústria } \\
\text { Transformação }\end{array}$} & \multicolumn{2}{|c|}{$\begin{array}{l}\text { Serv. Ind. } \\
\text { Público }\end{array}$} & \multicolumn{2}{|c|}{ Const. Civil } & \multicolumn{2}{|c|}{ Comércio } & \multicolumn{2}{|c|}{ Serviços } & \multicolumn{2}{|c|}{ Adm. Pública } & \multicolumn{2}{|c|}{ Agropecua } \\
\hline & $\mathrm{A}^{*}$ & $\mathrm{~B}^{* *}$ & $A^{*}$ & $\mathrm{~B}^{* *}$ & $\mathrm{~A}^{*}$ & $\mathrm{~B}^{* *}$ & $\mathrm{~A}^{*}$ & $\mathrm{~B}^{* *}$ & $\mathrm{~A}^{*}$ & $\mathrm{~B}^{* *}$ & $\mathrm{~A}^{*}$ & $\mathrm{~B}^{* *}$ & $\mathrm{~A}^{*}$ & $\mathrm{~B}^{* *}$ & $\mathrm{~A}^{*}$ & $\mathrm{~B}^{* *}$ \\
\hline Ext. Min. & $*$ & * & & & & & & & & & & & & & & \\
\hline Ind.Transf & 0,86 & 0,94 & * & * & & & & & & & & & & & & \\
\hline Serv.Ind. & 0,84 & 0,88 & 0,15 & 0,36 & $*$ & * & & & & & & & & & & \\
\hline Const.civi & 0,84 & 0,95 & 0,19 & 0,05 & 0,31 & 0,41 & * & * & & & & & & & & \\
\hline Comércio & 0,85 & 0,91 & 0,09 & 0,18 & 0,16 & 0,22 & 0,17 & 0,23 & * & * & & & & & & \\
\hline Serviço & 0,72 & 0,94 & 0,20 & 0,26 & 0,22 & 0,20 & 0,25 & 0,31 & 0,14 & 0,1 & * & * & & & & \\
\hline Adm. Pub. & 0,66 & 0,82 & 0,41 & 0,30 & 0,29 & 0,30 & 0,54 & 0,64 & 0,42 & 0,4 & 0,3 & 0,43 & * & * & & \\
\hline Agropec. & 0,57 & 0,72 & 0,55 & 0,44 & 0,46 & 0,44 & 0,66 & 0,81 & 0,59 & 0,6 & 0,5 & 0,55 & 0,25 & 0,28 & * & * \\
\hline
\end{tabular}

Fonte: Resultados de pesquisa

$A^{*}=$ em $2005 \quad B^{* *}=$ em 2015

Legenda: 0,01 $\leq$ Cag $\leq$ 0,32 = Associação Significativa; 0,33 $\leq$ Cag $\leq$ 0,67 = Associação Média; $0,68 \leq$ Cag $\leq 1,00$ = Fraca Associação $-(*)$ : Associação Total.

O setor de serviços teve forte associação com o setor da administração pública em 2005, e associação moderada em 2015. Por fim, o setor da administração pública teve forte associação com os setores da agropecuária, caça e pesca nos dois períodos analisados.

Dos treze municípios analisados, destacam-se quatro que conseguiram diversificar o dinamismo de base econômica. Entre eles, destacam-se Lagoa da Confusão (7), Formoso do Araguaia (6), Paraíso do Tocantins (10), Dueré (4). Os demais apresentam forte vínculo com a administração pública, ou seja, a maioria dos municípios ainda é dependente do funcionalismo público para que a força de trabalho exerça algum tipo de atividade produtiva. Isso não é diferente para os setores agrícolas, de extração vegetal, caça e pesca, que são atividades que movimentam grande parte da economia desses municípios, em especial as atividades agrícolas - que, em período de plantio e colheita, demanda muita 
força de trabalho -; e pecuária - que, em tempos de vacinação, compra e venda de gado, demanda maior quantidade de empregados.

Após a estimativa do quociente locacional e do coeficiente da associação geográfica para os municípios da microrregião de Rio Formoso, foi estimado o multiplicador de emprego com base nos valores do emprego básico e do emprego não básico para o período de 2005 e 2015 (Tabela 2). O multiplicador do emprego demonstra as condições que as atividades motoras têm para alavancar as condições de emprego e renda no local, ou melhor, o quanto cada emprego básico no município estimula a geração de empregos no setor não básico, lembrando que empregos básicos são empregos vinculados aos setores básicos da economia (que apresenta maior participação motora na geração de emprego na região, além de ter a maior parte de suas atividades produtivas voltadas para o mercado externo).

Tabela 2 - Multiplicador de emprego dos treze municípios da microrregião de Rio Formoso: 2005 e 2015

\begin{tabular}{c|l|c|c}
\hline Número & \multicolumn{1}{|c|}{ Municípios } & $\mathbf{2 0 0 5}$ & $\mathbf{2 0 1 5}$ \\
\hline 1 & Araguaçu & 5,83 & 2,61 \\
\hline 2 & Chapada da Areia & 1,71 & 1,42 \\
\hline 3 & Cristalândia & 10,82 & 2,25 \\
\hline 4 & Dueré & 3,48 & 1,93 \\
\hline 5 & Fátima & 3,08 & 2,68 \\
\hline 6 & Formoso do Araguaia & 4,57 & 3,84 \\
\hline 7 & Lagoa da Confusão & 3,02 & 3,16 \\
\hline 8 & Nova Rosalândia & 2,01 & 2,35 \\
\hline 9 & Oliveira de Fátima & 1,64 & 1,59 \\
\hline 10 & Paraíso do Tocantins & 3,41 & 3,47 \\
\hline 11 & Pium & 2,97 & 2,89 \\
\hline 12 & Pugmil & 3,04 & 2,16 \\
\hline 13 & Sandolândia & 2,27 & 2,09 \\
\hline- & Microrregião do Rio Formoso & 3,68 & 2,50 \\
\hline
\end{tabular}

Fonte: Resultados de pesquisa

Os valores do multiplicador de emprego apontaram para a seguinte conjuntura: em 2005, a média do multiplicador de emprego na microrregião de Rio Formoso foi de 3,68, ou seja, cada emprego básico na microrregião estimulava a geração de quase quatro empregos no setor não básico, evidenciando, assim, as condições que as atividades motoras têm para alavancar emprego e renda. Nesse caso, o emprego básico correspondeu a $4 \%$ do emprego 
total, e os empregos não básicos representaram $96 \%$ do total, o que caracteriza o efeito empuxo que o crescimento dos empregos básicos fomenta na economia da região.

Com destaque, observou-se que, em 2005, os seguintes municípios tiveram o multiplicador acima da média (3,68): Araguaçu, com 5,83; Cristalândia, com 10,82; e Formoso do Araguaia, com 4,57. Araguaçu e Cristalândia apresentaram os maiores multiplicadores de emprego em 2005. Esse aumento tende a estar relacionado às contrações dos setores da agricultura e da construção civil, neste último, especificamente, por causa de programas governamentais visando à implantação de novas obras de infraestrutura nessas localidades: pavimentação de estradas ligando-as aos maiores centros da microrregião, que são Paraíso do Tocantins e Formoso do Araguaia; construção de novas pontes, bueiros e galerias.

Em 2015, a média do multiplicador de emprego na microrregião de Rio Formoso baixou para 2,50, ou seja, houve uma redução na capacidade de gerar mais empregos. Com isso, houve desaceleração do ritmo das atividades econômicas na microrregião. Há possibilidade de as atividades produtivas básicas não implicarem a geração de emprego para os setores não básicos. Isso é raro de acontecer, pois a tendência de desenvolvimento da região é que haja investimento nos setores básicos e que, a partir do aumento da produção nesse setor, consequentemente, aumente a contratação da força de trabalho, gerando novos postos de emprego nos setores não básicos. Os municípios que apresentaram maiores índices do multiplicador do emprego em 2015 foram Araguaçu, com 2,61; Fátima, com 2,68; Formoso do Araguaia, com 3,84; Paraíso do Tocantins, com 3,47; e Pium, com 2,89.

A capacidade de multiplicar empregos é uma forte atração de população, pois, quanto maior a capacidade de multiplicar empregos, maior a capacidade de ampliação de postos de trabalho, bem como de diversificação de atividades e atração de mão de obra. Isso reforça a área de mercado do município, além do efeito polarizador exercido pela cidade de Paraíso do Tocantins, que tem o potencial mais significativo de criação de postos de trabalho. 


\section{Considerações finais}

Este artigo analisou o perfil de localização e o multiplicador de emprego das atividades produtivas em Rio Formoso. Foi aplicado o método de análise regional, com o uso dos indicadores quociente localização (QL), associação geográfica e do multiplicador de emprego. Os dados foram coletados junto ao Ministério do Trabalho e Emprego (2016) para os anos de 2005 e 2015.

A partir da análise dos dados, percebeu-se que, na distribuição percentual entre os treze municípios da microrregião analisados, o ramo de atividade que mais empregou foi a administração pública. Em alguns municípios, essa participação passou de $90 \%$ da geração de emprego, a exemplo de Chapada de Areia e Oliveira de Fátima. A atividade da administração pública se constituiu a principal empregadora, geradora de renda e de riqueza na microrregião do Rio Formoso. O setor de agropecuária, extração vegetal, caça e pesca constituiu o segundo maior empregador, seguido pelos setores do comércio, de serviços, indústria de transformação e construção civil. Esses setores representaram o motor da economia, o que proporcionou uma multiplicação de empregos na microrregião.

O setor de agropecuária, extrativismo, caça e pesca mostrou ser um grande dinamizador econômico em Rio Formoso, que, com os ramos da agricultura - soja, milho, pecuária, também proporcionou grande parte da geração de emprego da região. No entanto, a renda lograda pelos empresários da produção desse setor, em sua maioria, não permaneceu na região, sendo transferida para outras regiões do estado e para a capital, Palmas, que atrai fortemente os investimentos, limitando o crescimento e o desenvolvimento dos municípios dessa microrregião, não permitindo que sua riqueza, advinda dessa produtividade, tivesse sido, toda ela, reinvestida na economia local.

O terceiro setor mais influente foi o da indústria de transformação. Os ramos desse setor, na microrregião de Rio Formoso, que mais se destacaram foram os da fabricação de seixos e britas, cerâmicas e processamentos de grãos. Por mais que sejam atividades industriais e consideradas como de base para a economia da região, seus produtos são de baixo valor agregado e de baixa tecnologia adicionada à sua produção. Dessa forma, a indústria de transformação presente em Rio Formoso, além da baixa incorporação de valor 
econômico, não proporcionou, na formação de postos de emprego, alta produtividade por trabalhador, nem alto grau de especialização da força de trabalho.

Quanto ao multiplicador do emprego, sabe-se que esse mostrou as condições que as atividades motoras têm para alavancar as condições empregatícias, de renda e de riqueza no local. Observando os anos de 2005 e 2015, o multiplicador do emprego variou entre 1,65 10,82 (2005) e 1,42 - 3,84 (2015). A média, em 2005, foi de 3,68, e de 2,50 em 2015, ou seja, a capacidade de multiplicação de emprego, a partir da geração de emprego no setor básico, foi de 3,68 empregos no setor não básico em 2005, e 2,50 em 2015.

O coeficiente da associação geográfica dos setores produtivos da microrregião de Rio Formoso, para os anos de 2005 e 2015, evidenciou que há possibilidade de formação de clusters no setor de indústria de transformação, sendo atraente com os setores da construção civil, comércio e serviços. Constatou-se também que o setor de serviços contribuiu para a integração espacial da geoeconomia de Rio Formoso, atraindo as atividades produtivas para a microrregião.

Diante dessa conjuntura aqui tratada, fez-se necessário trilhar alguns caminhos e propor alternativas que promovam um desenvolvimento regional mais equitativo para a população da microrregião de Rio Formoso, e, por isso, sugere-se que sejam estimuladas ações em conjunto com os diversos atores econômicos, políticos e socais. Por exemplo, os municípios tratados nesta análise precisam encontrar estratégias para promover o desenvolvimento local. É necessário construir, com toda a sociedade local, um conjunto de alternativas, identificando suas potencialidades e fragilidades para a saída dessa situação. Para tanto, precisa-se buscar apoio junto aos governos estadual e municipal e construir planos de médio e longo prazo, já que o setor público é o principal empregador.

$\mathrm{Na}$ implantação de pequenas e médias indústrias na microrregião, é necessário incentivo - tanto do governo estadual quanto municipal - na concessão de terrenos para a atividade industrial, isenção de ICMS, melhoria da logística de escoamento da produção. Além destes, ainda, a liberação de créditos específicos para a atividade industrial, o que poderia promover impactos no aumento da produtividade do setor e, consequentemente, na geração de emprego e renda.

Portanto, é necessário que o papel dos atores locais, dos grupos empresariais, dos trabalhadores e dos políticos seja revisto, a fim de unir forças para atrair novos 
investimentos para a região, e que a governança, pautada na confiança e na transparência, possa fortalecer o empoderamento local.

\section{Referências}

ALVES, L. R. Indicadores de localização, especialização e estruturação regional. In: PIACENTI, C. A.; FERRERA DE LIMA, J. (Orgs.). Análise regional: metodologias e indicadores. Curitiba: Camões, 2012.

BARBOSA, Y. M. Conflitos sociais na fronteira amazônica: Projeto Rio Formoso. São Paulo: Papirus; Goiânia: Elegê, 1996.

DINIZ, C. C.; CROCCO, M. A. (Orgs.). Economia regional e urbana: contribuições teóricas recentes. Belo Horizonte: UFMG, 2006.

FERRERA DE LIMA, J.; ALVES, L. R. Localização, concentração e vantagem competitiva dos ramos produtivos na geoeconomia paranaense. Caderno de Geografia, Belo Horizonte, v. 18, n. 29, p. 98-124, 2008.

FRANÇA, A. A. O.; COSTA, K. G. A construção do território tocantinense por meio da cartografia das microrregiões. Revista Tocantinense de Geografia, 2016. Disponível em: <https://sistemas2.uft.edu.br:8004/index.php/geografia/article/view/2415>. Acesso em: 2 fev. 2017.

HADDAD, P. R. (Org.). Economia regional: teoria e métodos de análise. Fortaleza: BNB/Etiene, 1989.

IBGE - Instituto Brasileiro de Geografia e Estatística. IBGE Cidades. 2015. Disponível em: $<$ http://cidades.ibge.gov.br/painel/economia.php?codmun=170755>. Acesso em: 20 mar. 2015.

MINISTÉRIO DO TRABALHO E EMPREGO. MTE. Relação anual de informações sociais. 2005 e 2015. Disponível em: <http://portal.mte.gov.br/rais/>. Acesso em: 18 ago. 2016.

NORTH, D. C. Location theory and regional economic growth. Journal of Political Economy, v. 63, jun. 1955.

Teoria da localização e crescimento regional. In: SCHWARTZMAN, J. (Org.).

Economia regional: textos escolhidos. Belo Horizonte: CEDEPLAR/CETEDRE-MINTER, 1977. 
OLIVEIRA, N. M. Desenvolvimento regional do território do estado do Tocantins: implicações e alternativas. 2015. 224 f. Tese (Doutorado em Desenvolvimento Regional e Agronegócio) Universidade Estadual do Oeste do Paraná, Toledo, 2015.

OLIVEIRA, N. M.; NOBREGA, A. M.; MEDEIROS, M. R. Desenvolvimento econômico e regional segundo a Teoria de Base de Exportação. Revista Tocantinense de Geografia, v. 1, p. 76-96, 2012.

PIFFER, M. A Teoria da Base Econômica e o desenvolvimento regional do estado do Paraná no final do século XX. 2009. $167 \mathrm{f}$. Tese (Doutorado em Desenvolvimento Regional) Universidade de Santa Cruz do Sul, Santa Cruz do Sul, 2009.

Indicadores de base econômica. In: PIACENTI, C. A.; FERRERA DE LIMA, J. (Orgs.).

Análise regional: metodologias e indicadores. Curitiba: Camões, 2012.

RICHARDSON, H. W. Economia regional: teoria da localização, estrutura urbana e crescimento regional. Rio de Janeiro: Zahar, 1975.

SCHWARTZMAN, J. A teoria da base de exportação e o desenvolvimento regional. In:

HADDAD, P. R. (Org.). Desequilíbrios regionais e descentralização industrial. Rio de Janeiro: IPEA/INPES, 1975.

SOUZA, N. J. Conceito e aplicação da teoria da base econômica. Perspectiva econômica, Unisinos, São Leopoldo, v. 10, n. 25, p. 117-130, mar. 1980. 